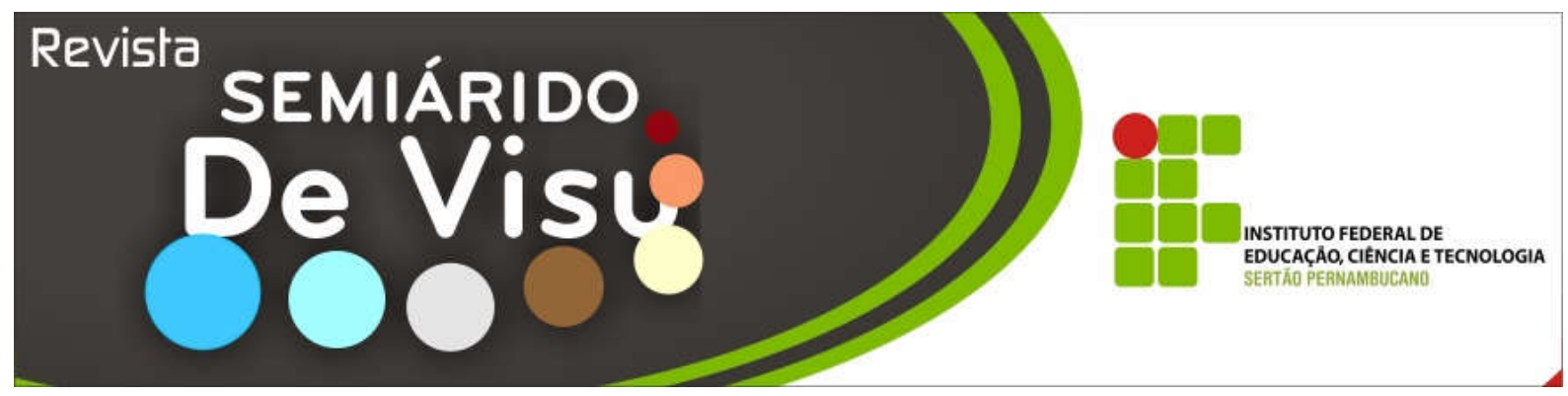

\title{
Soro do Queijo: uma alternativa tecnológica para enriquecimento de produtos cárneos
}

\author{
Simone Carvalho Leite ${ }^{1}$, Cristiane Ayala de Oliveira ${ }^{1}$, Bruna Farias de Souza ${ }^{1}$ \\ 1Setor de Tec nologia em Alimentos do Instituto Federal de Educ ação, Ciência e Tec no lo gia do Sertão Pernambucano - Campus \\ Salgueiro. BR 232, Km 508, sentido Recife, Zona Rural CEP: 56000-000 | Salgueiro/PE - Brasil. Fone:(87) 3421-0074. E-mail: \\ cristiane.ayala@ifsertao-pe.edu.br
}

RESUMO: O soro de leite é um subproduto resultante da produção convencional de queijos, considerado um resíduo altamente poluente em função da sua alta demanda bioquímica de oxigênio (DBO), fazendo-se necessário a utilização de alternativas para seu máximo aproveitamento, evitando ass im seu descarte no ambiente. Uma alternativa seria o emprego do soro do queijo em produtos cárneos como uma forma de enriquecer nutricionalmente, bem como, tecnologic amente. Portanto, este trabalho teve como objetivo fazer uma breve revisão ac erca do uso do soro do queijo em produtos cárneos, e verificar os resultados positivos e negativos obtidos em diversos produtos. A incorporação de soro de queijo em produtos cárneos é uma inovação, que propõe a elaboração de um alimento com maior valor nutricional e que busque solucionar o descarte inadequado deste resíduo na natureza. A bibliografia consultada demonstra que o uso deste subproduto é uma solução para o melhoramento de produtos cárneos processados, devido as suas carac terís ticas fís ico-químicas e bio ló gicas.

Palavras-chave: soro, c arne, ap roveitamento, le ite.

\section{Whey Cheese: a technological and nutritional alternative to enrichment of meat products}

\begin{abstract}
Whey is a by-product of conventional production of cheese, considered a highly polluting waste depending on its high biochemical oxygen demand (BOD), making it necessary to use alternatives to its maximum use, thus avoiding its disposal in environment. An alternative would be the use of cheese whey in meat products as a way to nutritionally enrich and technologic ally. Therefore, this study aimed to make a brief review on the use of whey cheese in meat products, and verify the positive and negative results in several products. The incorporation of whey in meat products is an innovation, which proposes the development of a food with higher nutritional value and that seeks to solve the inappropriate disposal of this waste in nature. The bibliography shows that the use of this by-product is a solution for the improvement of processed meat products, due to their physico-chemic al and biological characteris tics.
\end{abstract}

key words: whey, meat, recovery, milk. 
(LEITE; OLIVEIRA; SOUZA, 2015)

\section{Introdução}

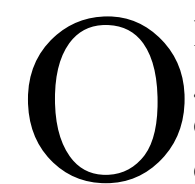
leite é uma secreção polifásica das glândulas mamárias, contendo $3,9 \%$ de gordura, $3,3 \%$ de proteínas, $5,0 \%$ de lactose e $0,7 \%$ de minerais. Em 2004 o Brasil assumiu uma importante posição de exportador de leite e derivados. Uma virada comercial importante, que contribuiu com uma série de ben efícios para diversos elos da cadeia produtiva, além de consolidar a posição do país no mercado internacional de lácteos, visto que exportar se traduz em alavancar a modernização do setor e manter o produtor na atividade (Ponchio et al., 2005).

O soro de leite é um produto fluido liberado na produção de queijos, por ser considerado um resíduo industrial altamente poluente devido a sua alta demanda bioquímica em função da sua grande quantidade de matéria orgânica, fazem-se necessários estudos e técnicas que busquem diminuir os impactos que este resíduo possa causar ao meio ambiente (Mizubuti, 1994; Bieger e Rinaldi, 2009). Pensando nisso tem sido muito empregado como ingrediente funcional em diversos produtos, tendo em vista as suas propriedades físico-químicas e biológicas além de apresentar excelentes propriedades tecnológicas, sua forma em pó pode ser adicionada em produtos cárneos embutidos, intensificando a cor destes produtos (Smithers, 2008; Daguer et al., 2010)

$A$ adição de soro de leite em produtos cárneos inibe a rancificação destes produtos, visto que as proteínas presentes nesse resíduo possuem a capacidade de estabilizar este tipo de reação (Peña-Ramos e Xiong, 2003; Pihlanto, 2006; Daguer et al., 2010). Segundo Terra et al. (2009), o principal fator de qualidade de uma massa cárnea é a sua estabilidade final, que está relacionada a capacidade desta massa de reter líquido.

Em produtos cárneos a caseína, que é uma proteína do leite presente também no soro, contribui para a emulsificação das gorduras, devido a sua alta capacidade em ligar água, melhorando assim a consistência do produto. Além disso, a adição de proteínas do soro de leite aumenta o rendimento dos produtos. $\mathrm{O}$ soro fluido tem sido utilizado na fabricação de mortadelas, em substituição de parte ou de toda a água presente no alimento, não alterando as características naturais desse produto e agregando valor nutricional ao mesmo (Terra et al., 2009).

Serdaroğlu (2006) fez estudos e testes com o objetivo de aumentar o teor de gordura em almôndegas adicionando soro de leite, no que concluiu que esta proposta seria viável e aceitável, vis to que a incorporação de $2 \%$ e $4 \%$ de WP não altera significativamente as propriedades sensoriais de almôndegas, no entanto, resulta em maior rendimento, aumento da gordura e valores de retenção de umidade e suculência.

De forma geral a distribuição ou revenda do soro de queijo para o uso em produtos cárneos permite reduzir o custo com o tratamento de efluentes e, até mesmo, gerar receita para o setor, além de prever a substituição da água por um produto com elevado valor proteico e de preço relativamente baixo que, além de favorecer a qualidade nutricional, pode contribuir para as propriedades tecnológicas do produto, privilegiando a qualidade. Portanto, este trabalho tem por objetivo fazer uma revisão bibliográfica acerca da utilização do soro de queijo em produtos cárneos.

\section{Material e Métodos}

Este estudo constituiu-se de uma revisão da literatura especializada, realizada entre Agosto de 2014 e maio de 2015, no qual realizou-se uma consulta a livros e periódicos presentes na Biblioteca da Instituto Federal de Educação, Ciência e Tecnologia do Sertão Pernambucano - Campus Salgueiro e por artigos científicos selecionados através de busca no banco de dados do scielo e da Science Direct. A pesquisa dos artigos foi realizada entre setembro de 2014 e Abril de 2015. As palavras-chave utilizadas na busca foram soro de leite, soro de leite fluido, soro de queijo, proteínas não cárneas e produtos cárneos. Os critérios de inclusão para os estudos encontrados foram à abordagem tecnológica da 
utilização do soro do queijo em produtos cárneos. Foram excluídos estudos que relatavam o emprego de outras modalidades da utilização do soro. Logo em seguida, buscou-se estudar e compreender os principais parâmetros e formas de aplicação do soro empregados nos estudos encontrados.

\section{Resultados e Discussão}

\section{O soro como subproduto}

O soro é um abundante subproduto disponível da indústria de queijo que já foi considerado como resíduo, sendo utilizado para alimentação animal ou descarte. Atualmente é considerado uma fonte valiosa de proteínas e é amplamente usado como um ingrediente alimentar (Bottomley et al., 1990; Mulvihill e Ennis, 2003) para melhorar características funcionais incluindo a gelificação, formação de espuma e emulsificação, bem como propriedades nutricionais (Burrington, 1998; De Wit, 1998).

O soro do leite é obtido através do processamento do queijo, no qual a caseína é insolubilizada no seu ponto isoelétrico pela ação da renina, sendo o líquido reman escente chamado de soro doce. Pode também ser obtido por precipitação ácida, sendo chamado de soro ácido. Os tipos de soro obtidos por esses dois diferentes processos apresentam composições diferentes, contém aproximadamente $20 \%$ das proteínas totais do leite. Constituído de, em média, $4,9 \%$ de lactose, $0,6 \%$ de sais minerais, $0,3 \%$ de gordura e $0,00012 \%$ de riboflavina, representa uma mistura de proteínas $(0,9 \%)$ com importantes propriedades físicas, químicas e funcionais, desempenhando papel na nutrição, como uma fonte excepcionalmente rica e balanceada de aminoácidos essenciais de elevada digestibilidade e rápida absorção.

Segundo Venturini Filho (2010), a composição de aminoácidos das proteínas do soro ultrapassa os níveis de todos os aminoácidos essenciais da proteína de referência da FAO (Food and Agriculture Organization), caracterizando-as assim como proteínas de alto valor biológico e de boa digestibilidade.
As proteínas do soro de leite são rapidamente absorvidas pelo organismo, o que estimula a síntese de proteínas sanguíneas e teciduais, tanto que alguns pesquisadores classificaram essas proteínas como proteínas de metabolização rápida, muito importantes para situações de stress metabólico, onde a reposição de proteínas no organismo se torna emergencial (Sgarbieri, 2004). Além disso apresentam a capacidade de formar géis quando aquecido acima de $70^{\circ} \mathrm{C}$ (Langley e Green, 1989). As proteínas do soro são proteínas globulares tensoativas e podem ser adsorvidas na interface água/gordura em que elas se desenvolvem, e apresentam o potencial de estabilizar os glóbulos de gordura dentro de uma matriz alimentar (Huffman, 1996; Sun et $a l ., 2007)$. Tais propriedades funcionais fazem das proteínas de soro de leite um aditivo útil para a produção de emulsões de carne e, por conseguinte, utilizar pode ser utilizado para melhorar a emulsificação, retenção de água e da textura (Holland, 1984).

Apesar do seu elevado valor nutricional, o soro de leite é considerado um grande problema para a indústria de laticínios, uma vez que, quando não aproveitado, torna-se um resíduo extremamente difícil e oneroso de se tratar. O descarte de soro não constitui apenas um problema de não aproveitamento de um material que contém um teor de nutrientes considerável, mas também de um problema de poluição ambiental de elevada significância, devido a sua alta concentração de matéria orgânica. Um litro de soro (com $0,05 \%$ de gordura) possui uma Demanda Bioquímica de Oxigênio (DBO) de $45.000 \mathrm{mg} / \mathrm{L}$ (Bylund, 1995), o que corresponde a cerca de 100 vezes o valor da DBO gerada pelo esgoto doméstico, sendo a implantação de um sistema de tratamento biológico do soro nos laticínios de elevado custo.

Países como Estados Unidos, Austrália, Canadá e Nova Zelândia e nações da União Européia processam este subproduto reconhecendo-o como ingrediente funcional e agregando valor à linha de produção da indústria látea. No Brasil, os dados sobre a disponibilidade do soro de leite são altamente imprecisos (Antunes, 2003), mas boa parte do 
(LEITE; OLIVEIRA; SOUZA, 2015)

queijo é produzida por pequenas empresas que, evitando o custo do tratamento deste efluente e sem fiscalização efetiva das autoridades, optam pela utilização parcial deste subproduto como alimentação animal, descartando o excedente diretamente nos rios. Sendo uma das mais potentes de todas as águas residuais da indústria láctea (Orchard, 1972), e tendo estimativa de produção mundial de 145 bilhões de $\mathrm{kg}$ por ano (Parsons et al.).

O não aproveitamento do soro é geralmente oriundo da carência de processos tecnológicos mais simples para o seu processamento em produtos de maior valor agregado. $\mathrm{O}$ soro líquido pode ser usado diretamente na formulação de muitos produtos destinados ao consumo humano, ou então, convertido a uma série de concentrados e isolados proteicos para uso como aditivos nestes produtos. A indústria de carnes, por exemplo, tem usado, cada vez mais, concentrados ou isolados protéicos de soro de queijo, ou mesmo soro de queijo em pó, na formulação de produtos que sofrem o processo de trituração (Yetim et al., 2006).

Neste sentido, o uso de produtos lácteos como ingredientes na formulação de produtos cárneos têm sido intensamente investigados (Lee et al., 1980; Ellekjaer et al., 1996; Muguruma et al., 2003), uma vez que as proteínas do leite possuem boa capacidade em ligar água e, embora possuam uma baixa capacidade emulsificante em termos de base protéica, também atuam como estabilizadores em produtos emulsionados. No entanto, informações sobre o uso da incorporação de soro de queijo fluido em produtos cárneos ainda não estão amplamente disponíveis. Marriott et al. (1998) substituiu a água de formulação de produtos reestruturados de suínos, formulados com baixo teor de gordura, por soro líquido, reportando que $30 \%$ de soro fluido pode ser incorporado ao produto sem alterar a sua aparência, sabor ou estabilidade.

\section{Aplicabilidade em produtos cárneos}

De acordo com (Van Den Hoven, 2000) a aplicação do soro de quiejo em produtos cárneos reestruturados ou secionados $\mathrm{e}$ enformados, favorece a capacidade de liga entre as peças cárneas, com conseqüente melhora na fatiabilidade, além de contribuir para o rendimento do processo. Vários estudos têm sido conduzidos para viabilizar a utilização de proteínas do soro de queijo na elaboração de diferentes produtos cárneos, avaliando principlmente os efeitos de sua adição na qualidade sensorial e tecnológica do produto (Chen e Trout, 1991; El-Magoli et al., 1996; Lyons et al., 1999; Barbut, 2006), mas, a grande maioria tem feito uso do concentrado de proteína de soro; isolado de proteína de soro ou soro em pó, que são produtos mais caros em virtude da tecnologia empregada para sua obtenção. Existem poucas informações sobre a prática de incorporar o soro de leite fluído em produtos cárneos cominuídos Terra et al. (2009) e Yetim et al. (2006).

Alguns autores afirmam que a adição de soro do queijo em produtos cárneos promove um incremento positivo em aspectos sensoriais como no caso de Yetim et al. (2001) que ao adicionar soro de queijo na formulação de salsichas tipo Frankfuters, não observaram alterações nos atributos sensoriais de textura, sabor, cor, aroma e suculência quando da substituição de toda água da formulação por soro de queijo. Estes autores também observaram que à medida que a concentração de soro de queijo na formulação era aumentada, a estabilidade da emulsão formada, avaliada sensorialmente, também aumentava. $\mathrm{O}$ mesmo favorecimento da estabilidade da emulsão foi observado por Zorba et al. (1995) para um sistema modelo de emulsão cárnea. Os resultados anteriormente citados também corroboram com os reportados por Terra et al. (2009) que ao verificar a possibilidade de incorporar soro de leite líquido em mortadela substituindo a água obteve uma redução na gordura liberada pelo produto após tratamento térmico nos tratamentos em que a água foi substituída por 75 e $100 \%$ de soro de leite, que na mortadela com $100 \%$ de gelo, bem como não foram constatadas alterações nas características físico-quimicas do produto. $\mathrm{O}$ referido autor também verificou que tal tratamento não exerceu influência significativa nas características sensoriais, $\mathrm{pH}$, coloração, 
estabilidade da emulsão e liquido liberado após o tratamento térmico das mortadelas.

Yetim et al. (2006), quando substituíram o gelo usado na formulação de salsicha Frankfurt por 25, 50, 75 e 100\% de soro de leite, obtiveram percentual de separação de gordura bem inferior àquele em que empregaram apenas o gelo, em todas as proporções testadas. Zorba e Gokalp (1998) verificaram que o soro líquido teve efeito positivo nas características da emulsão em sistema modelo cárneo. Já Revilla et al. (2007) afirmam que a proteína caseína presente no soro de leite, eleva a capacidade de formar emulsão, segurar água e melhorar a textura do produto, o que junto a isto, atende os anseios da indústria de alimentos, e fornece qualidade nutricional e sensorial para o processo de fabricação (Minim, 2006; Nunes et al., 2011; Dutra et al., 2012). Hayes et al. (2006) e Szerman et al. (2007) utilizaram proteínas do leite em produtos cárn eos, e obtiveram aumento da capacidade de retenção de água (CRA). Para Martins e Burket (2009), o acréscimo de soro de leite em um produto, seja ele lácteo ou cárneo, implica no aumento da disponibilidade de lactose no meio, no incremento de proteína e na retenção de água, obtendo melhores características tecnológicas no produto acabado. Outro ponto é que o conteúdo de carboidratos do soro do leite pode influenciar as características texturais quando acrescidos em produtos cárneos pois conforme Hachmeister e Herald (1998) os carboidratos podem acentuar a firmeza e outras características texturais em produtos de teores reduzidos de gordura. É percebido que essas substâncias mimetizam a cremosidade e a maciez, pela redução da gordura, e promovem a retenção da umidade, aumento no volume dos sólidos e aumento da viscosidade (Fennema, 1996). Paradis e Mungal (1984) ao avaliarem os efeitos da utilização de soro em pó como o único carboidrato fermentável acrescentado em características sensoriais, físicas e químicas de embutido fermentado produzido em condições industriais constataram $o$ potencial de utilização como a única fonte de carboidrato fermentável para Pepperoni.
No entanto, existe uma preocupação com relação a lactose, que pode vir a produzir a descoloração nos produtos à base de carne, devido à reação de Maillard (Mortensen, 1986), segundo Araújo (2011) e Coultate (2004), a lactose é um açúcar redutor e promove reações de escurecimento, modificando a tonalidade da cor rósea para rosa escuro em produtos cárneos. $\mathrm{Na}$ etapa de cozimento a formação destes pigmentos não é apenas acelerada, mas a sua intensidade também é aumentada (Araújo, 2011). Contudo, Dutra et al. (2012) não encontraram diferença significativa na análise sensorial de apresuntados elaborados com $100 \%$ de soro de leite em substituição da água de formulação; Yetim et al. (2001) não encontraram diferenças significativa nos atributos de cor representados pelos valores $L^{*}$, $a^{*}$ e b*. Terra et al. (2009), ao substituírem água por soro de leite também não encontraram alteração de forma significativa na coloração e análise sensorial de mortadela. Dutra et al. (2012) perceberam o desenvolvimento de sabor estranho com a adição de pequenas quantidades de soro de leite líquido no produto. Marriott et al. (1998) não encontraram diferenças na suculência, maciez, sabor ou descoloração visual, também avaliados por uma equipe de provadores treinada. Ellekjaer et al. (1996) relataram maior desenvolvimento de sabor e $\mathrm{v}$ iscosidade em salsichas cozidas contendo maiores teores de proteína de soro de leite. Segundo alguns autores um dos problemas associados com produtos de baixo teor de gordura é referente à diminuição do sabor característico do produto (Ramos e Gomide, 2007; Botega, 2009; Chinait, 2009).

Wójciak et al. (2014) ao determinar os efeitos de soro de leite ácido com sementes de mostarda nas propriedades físico-químicas, especialmente a formação de cor, estabilidade microbiana e na qualidade sensorial de salsicha cozida durante o armazenamento frio obteve efeitos positivos sobre as características físicoquímicas e sensoriais de salsicha orgânica permitindo a possibilidade do produto ser armazenado a temperatura de refrigeração até 30 dias, em sacos de vácuo com boa aceitabilidade. Os resultados deste autor sugeriram também que as atividades 
antioxidantes dos compostos de soro de leite aliados as sementes de mostarda possibilitou a estabilização do anel de porfirina da molécula heme durante a armazenagem de forma tão eficaz como sal de cura. O parâmetro de cor, aspecto visual e a qualidade global das amostras orgânicas com sementes de mostarda foram semelhantes aos controles com um agente de cura. Além disso, a semente de mostarda e soro de leite ácido contém alguns componentes que fornecem a característica cor rosada de carnes curadas nitritos.

\section{Conclusões}

Conclui-se que o emprego de soro de queijo em produtos cárneos é uma tecnologia viável, vis to que este subproduto possui grande valor nutricional e que possui características funcionais, o que pode agregar valor a estes produtos sem modificar suas características naturais. Vale salientar que essa inovação propõe um destino mais útil e nobre para este fluido considerado altamente poluente, evitando que este seja descartado de maneira inadequada, prejudicando o meio ambiente. Outro ponto relevante é que a comercialização deste subproduto seria mais uma fonte de renda para os produtores e setores de laticínios.

Desta forma, a utilização do soro de queijo fluido em produtos cárneos fragmentados, oferece um elevado potencial para a fortificação e melhora das características tecnológicas durante o seu processamento, sem implicar em custos elevados do préprocessamento do soro, uma vez que é necessária apenas a sua coleta higiênica e pasteurização. Por fim, a obtenção de mais informações, de ordem técnica e científica, inclusive com análises objetivas de parâmetros importantes como textura e cor, sobre a incorporação de soro de queijo fluido em produtos cárneos, para produzi-los com elevada qualidade.

\section{Referências Bibliográficas}

ANTUNES, A. J. Funcionalidade de proteínas do soro de le ite bovino. 2003.
ARAÚJO, J. M. Químic a de a limentos: teoria e prática. 5 ed. Viçosa,MG: 2011. 601.

BARBUT, S. Effects of caseinate, whey and milk powders on the texture and microstructure of emulsified chicken meat batters. LWT Food Science and Technology, v. 39, n. 6, p. 660-664, 8// 2006. ISSN 0023-6438. Disponível em: < http://www.sciencedirect.com/science/article/pi $\mathrm{i} / \mathrm{S} 0023643805000939>$.

BIEGER, A.; RINALDI, R. N. Reflexos do reaproveitamento de soro de leite na cadeia produtiva de leite do oeste do Paraná. . In: ANAIS DO CONGRESSO DA SOCIEDADE BRASILEIRA DE ECONOMIA, A. E. S. R., CONGRESSO DA SOCIEDADE BRASILEIRA DE ECONOMIA, ADMINISTRAÇÃO E SOCIOLOGIA RURAL, 2009, Porto Alegre.

BOteGA, L. M. G. E. A. Avaliação da cor objetiva de apresuntados elaborados com diferentes concentrações de soro de leite. CONGRESSO BRASILEIRO DE

HIGIENISTAS DE ALIMENTOS. UFSC.

Florianópolis: Anais...: 5 p. 2009.

BOTTOMLEY, R. C.; EVANS, M. T. A.; PARKINSON, C. J. Whey Proteins. In: HARRIS, P. (Ed.). Food Gels: Springer Netherlands, 1990. cap. 11, p.435-466. (Elsevier Applied Food Science Series). ISBN 978-94-010-6825-3.

BURRINGTON, K. J. More than just milk Food Product Design, v. 7 n. 10, p. pp. 91111, 1998.

BYLUND, G. Dairy Processing Handbook. . Lund, Sweeden: 1995.

CHEN, C. M.; TROUT, G. R. Sensory, Instrumental Texture Profile and Cooking Properties of Restructured Beef Steaks Made with Various Binders. Journal of Food Science, v. 56, n. 6, p. 1457-1460, 1991. ISSN 1750-3841. Disponível em: < $\mathrm{http}: / / \mathrm{dx}$. doi.org/10.1111/j.13652621.1991.tb08615.x $>$. 
CHINAIT, T. M. N. E. A. Avaliação da cor objetiva de presuntos e apresuntados comerciais. CONGRESSO BRASILEIRO DE CIÊNCIA E TECNOLOGIA DE CARNES. ITAL. Campinas: São Paulo: Anais... 5 p. 2009.

COUltate, T. P. Alimentos: a química de seus componentes. Porto Alegre: 2004. 368 p.

DAGUER, H.; STEPHAN, M. P.; BERSOT, L. D. S. Perfil eletroforético de lombo suíno adicionado de proteínas não cárneas. Ciência Rural, v. 40, p. 404-410, 2010. ISSN 01038478. Disponível em: < http://www.scielo.br/scielo.php?script=sci_artt ext\&pid=S0103-

$84782010000200028 \& \mathrm{nrm}=$ iso $>$.

DE WIT, J. N. Nutritional and Functional Characteristics of Whey Proteins in Food Products. Journal of Dairy Science, v. 81, n. 3, p. 597-608, 3// 1998. ISSN 0022-0302. Disponível em: < http:/www.scienced irect.com/science/article/pi $\mathrm{i} / \mathrm{S} 0022030298756139>$.

DUTRA, M. P. et al. Technological and sensory quality of restructured low-fat cooked ham containing liquid whey. Ciência e Agrotecnologia, v. 36, p. 86-92, 2012. ISSN 1413-7054. Disponível em: < http:/www.scielo.br/scielo.php?script=sci $\operatorname{artt}$ ext\&pid $=$ S1413$\underline{70542012000100011 \& \mathrm{nrm}=\text { iso }}>$.

EL-MAGOLI, S. B.; LAROIA, S.; HANSEN, P. M. T. Flavor and texture characteristics of low fat ground beef patties formulated with whey protein concentrate. Meat Science, v. 42, n. 2, p. 179-193, // 1996. ISSN 0309-1740. Disponível em: < http:/www.scienced irect.com/science/article/pi $\mathrm{i} / 0309174095000321>$.

ELLEKJAER, M. R.; NAES, T.; BAARDSETH, P. Milk Proteins Affect Yield and Sensory Quality of Cooked Sausages. Journal of Food Science, v. 61, n. 3, p. 660666, 1996. ISSN 1750-3841. Disponível em: < http://dx.doi.org/10.1111/j.1365$\underline{2621.1996 . t b 13181 . x}>$.

FENNEMA, O. R. Food chemistry. $3^{\text {rd }}$ ed. New York: 1996.

HACHMEIS TER, K.; HERALD, T. Thermal and rheological properties and textural attributes of reduced-fat turkey batters. Poultry Science, v. 77, n. 4, p. 632-638, April 1, 1998 1998. Disponível em: < http://ps.oxfordjournals.org/content/77/4/632.a $\underline{\text { bstract }}>$.

HAYES, J. E. et al. The effect of enhancement with salt, phosphate and milk proteins on the physical and sensory properties of pork loin. Meat Science, v. 72, n. 3, p. 380-386, 3// 2006. ISSN 0309-1740. Disponível em: < http://www.sciencedirect.com/science/article/pi $\mathrm{i} / \mathrm{S} 0309174005001981$ >.

HOLLAND, G. C. A meat in dustry perspective on the use of dairy ingredients. Proceedings of canadian dairy ingredients in the food industry p. 1-19 Ottawa, 1984.

HUFFMAN, L. M. Processing whey protein for use as a food ingredient. Food Technology, v. 50, n. 2, p. 49-52, 1996. Disponível em: < $\mathrm{http}: / / \mathrm{www}$. scopus.com/inward/record.url? eid= $\underline{2-\mathrm{s} 2.0-}$

0030083791\&partnerID $=40 \& \mathrm{md} 5=\mathrm{e} 6686 \mathrm{c} 8 \mathrm{a} 76$ 43344f2b00687ba136c09e $>$.

LANGLEY, K. R.; GREEN, M. L. Compression and impact strength of gels, prepared from fractionated whey proteins, in relation to composition and microstructure. Journal of Dairy Research, v. 56, n. 02, p. 275-284, 1989. ISSN 1469-7629. Disponível em:

http://dx.doi.org/10.1017/S0022029900026480 >. Acesso em: 1989.

LEE, A.; CANNON, R. Y.; HUFFMAN, O. L. WHEY PROTEIN CONCENTRATES IN A PROCESSED MEAT LOAF. Journal of Food Science, v. 45, n. 5, p. 1278-1279, 1980. ISSN 1750-3841. Disponível em: < http://dx.doi.org/10.1111/j.13652621.1980.tb06537.x >. 
LYONS, P. H. et al. The influence of added whey protein/carrageenan gels and tapioca starch on the textural properties of low fat pork sausages. Meat Science, v. 51, n. 1, p. 43-52, 1// 1999. ISSN 0309-1740. Disponível em: < http://www.sciencedirect.com/science/article/pi i/S0309174098000953 >.

MARRIOTT, N. G. et al. A RESEARCH NOTE EVALUATION OF RESTRUCTURED LOW-FAT HAM CONTAINING WHEY. Journal of Muscle Foods, v. 9, n. 2, p. 201207, 1998. ISSN 1745-4573. Disponível em: < http://dx.doi.org/10.1111/j.1745-

$\underline{4573.1998 . t b 00655 . x}>$.

MARTINS, A. R.; BURKET, C. A. V. Revisão galacto-oligossacarídeos (GOS) e seus efeitos prebióticos e bifidogênicos. Brazilian Journal Food Technology. Campinas. 1-15: 230-240 p. 2009.

MINIM, V. P. R. Análise sensorial: estudos com consumidores. Viçosa, MG: 2006. 255.

MIZUBUTI, I. Y. Soro de Leite: Composição, processamento e utilização na alimentação. Semina Ciências Agrá rias, v. 15, n. 1, p. 8094, 1994.

MORTENSEN, B. K. The use of milk powder in food products. In: HAGUE., T. (Ed.). Proc. Int. Dairy Cong, 1986. p.707-717.

MUGURUMA, M. et al. Soybean and milk proteins modified by transglutaminase improves chicken sausage texture even at reduced levels of phosphate. Meat Science, v. 63, n. 2, p. 191-197, 2// 2003. ISSN 0309-1740. Disponível em: < http://www.sciencedirect.com/science/article/pi $\mathrm{i} / \mathrm{S} 0309174002000700>$.

MULVIHILL, D. M.; ENNIS, M. P. Functional Milk Proteins: Production and Utilization. In: FOX, P. F. e MCSWEENEY, P. L. H. (Ed.). Advanced Dairy Chemistry-1 Proteins: Springer US, 2003. cap. 32, p.1175-1228. ISBN 978-0-306-47271-8.

NUNES, C. A.; PINHEIRO, A. C. M.; BASTOS, S. C. EVALUATING CONSUMER
ACCEPTANCE TESTS BY THREE-WAY

INTERNAL PREFERENCE MAPPING OBTAINED BY PARALLEL FACTOR ANALYSIS (PARAFAC). Journal of Sensory Studies, v. 26, n. 2, p. 167-174, 2011. ISSN 1745-459X. Disponível em: < http://dx.doi.org/10.1111/j.1745459X.2011.00333.x $>$.

ORCHARD, R. L. Wastes and effluent requirements of the dairy industry. American Dairy Review, v. 45, n. n.5, p. 45-57, 1972.

PARADIS, D. C.; MUNGAL, M. Whey Utilization In Fermented Sausage Evaluation Of Chemical, Sensory and Physical Characteristics. Canadian Institute of Food Science and Technology Journal, v. 17, n. 1, p. 44-47, 1// 1984. ISSN 0315-5463. Disponível em:

http://www.sciencedirect.com/science/article/pi i/S0315546384723157>.

PARSONS, J. G. et al. Acceptability of Ice Cream Made with Processed Wheys and Sodium Caseinate1. Journal of Dairy Science, v. 68, n. 11, p. 2880-2885, Disponível em: < http://dx.doi.org/10.3168/jds.S00220302(85)81181-4 >. Acesso em: 2015/05/31.

PEÑA-RAMOS, E. A.; XIONG, Y. L. Whey and soy protein hydrolysates inhibit lipid oxidation in cooked pork patties. Meat Science, v. 64, n. 3, p. 259-263, 7// 2003. ISSN 0309-1740. Disponível em: < http://www.sciencedirect.com/science/article/pi i/S0309174002001870 >.

PIHLANTO, A. Antioxidative peptides derived from milk proteins. International Dairy Journal, v. 16, n. 11, p. 1306-1314, 11// 2006. ISSN 0958-6946. Disponível em: < http://www.sciencedirect.com/science/article/pi i/S0958694606001488 >.

PONCHIO, L. A.; GOMESOMES, A. L.; PAZ, E. Perspectivas de consumo de leite no Brasil. CEPEA Boletim do Leite, v. 24, n. n.130, p. 2-6, 2005.

RAMOS, E. M.; GOMIDE, L. A. M. Avaliação da qualidade de carnes: 
fundamentos e metodologias. . Viosa:MG: 2007.

REVILLA, I.; RODRÍGUEZ-NOGALES, J. M.; VIVAR-QUINTANA, A. M. Proteolysis and texture of hard ewes' milk cheese during ripening as affected by somatic cell counts. Journal of Dairy Research, v. 74, n. 02, p. 127-136, 2007. ISSN 1469-7629. Disponível em:

http://dx.doi.org/10.1017/S0022029906002342

>. Acesso em: 2007.

SERDAROĞLU, M. Improving low fat meatball characteristics by adding whey powder. Meat Science, v. 72, n. 1, p. 155-163, 1// 2006. ISSN 0309-1740. Disponível em: < http://www.sciencedirect.com/science/article/pi i/S0309174005002603 >.

SGARBIERI, V. C. Propriedades fisiológicasfuncionais das proteínas do soro de leite. Revista de Nutrição, v. 17, p. 397-409, 2004. ISSN 1415-5273. Disponível em: < http:/www.scielo.br/scielo.php?script=sci artt ext\&pid $=$ S1415$\underline{52732004000400001 \& \mathrm{nrm}=\text { iso }}>$.

SMITHERS, G. W. Whey and whey proteinsFrom 'gutter-to-gold'. International Dairy Journal, v. 18, n. 7, p. 695-704, 7// 2008. ISSN 0958-6946. Disponível em: < http://www.sciencedirect.com/science/article/pi i/S0958694608000344 >.

SUN, C.; GUNASEKARAN, S.; RICHARDS, M. P. Effect of xanthan gum on physicochemical properties of whey protein isolate stabilized oil-in-water emulsions. Food Hydrocolloids, v. 21, n. 4, p. 555-564, 2007. Disponível em:

http://www.scopus.com/inward/record.url?eid= 2-s2.0-

$33846211089 \&$ partnerID $=40 \& \mathrm{md} 5=643 \mathrm{acc} 230$ 3cea1a7341cb2d8b5cc314e $>$.

TERRA, N. N. et al. Emprego de soro de leite líquido na elaboração de mortadela. Ciência Rural, v. 39, p. 885-890, 2009. ISSN 01038478. Disponível em: < http:/www.scielo.br/scielo.php?script=sci_artt
ext\&pid=S0103$\underline{84782009000300038 \& \mathrm{nrm}=\mathrm{iso}}>$.

VAN DEN HOVEN, M. Dairy Ingredient: Applications in Meat, Poutry and Seafood. In: SONS, J. W. (Ed.). FRANCIS, F.J.: Encyclopedia of Food Science and Technology.: New York, 2000. p. p.460-469.

VENTURINI FILHO, W. G. Bebidas não alcoólic as: Ciência e Tecnologia. . São Paulo: 2010.

YETIM, H. et al. USING FLUID WHEY IN COMMINUTED MEAT PRODUCTS: EFFECTS ON TEXTURAL PROPERTIES OF FRANKFURTER-TYPE SAUSAGES. Journal of Muscle Foods, v. 17, n. 3, p. 354366, 2006. ISSN 1745-4573. Disponív el em: < http://dx.doi.org/10.1111/j.1745-

$\underline{4573.2006 .00055 . x}>$.

YETIM, H.; MÜLLER, W. D.; EBER, M. Using fluid whey in comminuted meat products: effects on technological, chemical and sensory properties of frankfurter-type sausages. Food Research International, v. 34, n. 2-3, p. 97-101, // 2001. ISSN 0963-9969. Disponível em: < http://www.sciencedirect.com/science/article/pi i/S0963996900001356 >.

ZORBA, O. et al. The possibility of using fluid whey in comminuted meat products: capacity and viscosity of the model emulsions prepared using whey and muscle proteins. Zeitschrift für Lebensmittel-Untersuchung und Forschung, v. 200, n. 6, p. 425-427, 1995/11/01 1995. ISSN 0044-3026. Disponível em: < http://dx.doi.org/10.1007/BF01193251 >.

ZORBA, S. O.; GOKALP, H. Y. Stability of model emulsions prepared using whey and muscle proteins. Die Nahrung, v. 42, p. 16-18, 1998. 